\title{
Mental health among healthcare providers
}

\author{
Rebecca G. Rogers ${ }^{1}$
}

Received: 4 March 2021 / Accepted: 4 March 2021 / Published online: 17 April 2021

(C) The International Urogynecological Association 2021

In this issue of the IUJ, we publish a special contribution in honor of Dr. Nikolaus Veit-Rubin, who passed away on January 20, 2021. The topic is critical: mental health among health care providers. Providers' mental health is besieged by the daily demands of providing clinical care and is further complicated by the pandemic. Unfortunately, many of the mental health stabilizers that providers had in place to offset work stress are no longer available, such as meeting with friends, travel and, importantly, physical human contact. At times, we are unable to care for our patients when restrictions are in place, and women cannot have the operations that they need. The onslaught is in both our personal and professional worlds.

Unfortunately, providers are at high risk for mental health disorders and an increased risk for suicide. As outlined in Dr. Patel's article, part of this is due to the qualities that many physicians have including internal drive, dedication, self-discipline, perfectionism and self-criticism. These attributes initiate a perfect storm, which can lead to anxiety and depression, which increases the risk of self-harm. Many providers are afraid that acknowledging mental health concerns will jeopardize their ability to practice medicine and limit their license. Although these fears may be real, they serve to perpetuate the challenges that providers face in receiving the care that they need.

What should be done about provider mental health and burnout? First, recognize the problem. This includes either reaching out to those who seem to be struggling to see if they need help or self-reflecting on our own feelings and frustrations and what we need to do to address them. Many institutions have resources for providers to seek counseling or coaching for specific challenges. Second, normalize helpseeking. Transparent conversations about mental health resources and support of accessing them can do a lot to diminish the taboo of seeking care. Third, embrace self-care. While we may know that if we cannot take care of ourselves, we cannot take care of others, it is challenging to put this into action by taking time to rest, reconnect and renew. We all need a break now and then no matter how many patients need to be seen or surgeries need to be performed.

Publisher's note Springer Nature remains neutral with regard to jurisdictional claims in published maps and institutional affiliations.
Rebecca G. Rogers

rogersr2@amc.edu

1 Albany Medical Center, Albany, NY, USA 